\title{
Performance Measurement Systems (PMSs) in Educational Administration in Saudi Arabia
}

\author{
${ }^{1}$ Ali Aseeri, ${ }^{2}$ Fatemah Alhazmi \\ ${ }^{1}$ College of management, King Khaled University \\ ${ }^{2}$ College of Education, Taibah University
}

\begin{abstract}
This research is undertaken in an educational setting in Saudi Arabia to develop an empirical understanding of PMSs and its relationship with organisational factors. The research aims to understand the perceived concept of PMSs in the Saudi educational administration, how they are developed perceived and used, and identify contextual factors affecting the way PMSs are practiced. A qualitative methodology is employed using structured interviews as a research tool. Four major themes has been created each with related sub-themes. Major themes are: the concept of PMSs, the development and implementation and the organisational factors affecting PMSs. The research found that several departments in the ministry of education should be responsible of PMSs but only one department is working on them with basic steps to develop the indicators. In addition, the factors appear to affect the way of PMSs are centralization, lack of cooperation and culture.
\end{abstract}

\section{Introduction}

Establishing objectives is one of the basic steps of any organisation in public or private sectors however, managers need to evaluate whether these objectives have been achieved and developed as well. Performance measurement is a critical part of the management process that aims universally to assess how well someone or something has done against set objectives.

Since 1999, performance measurement has been widely spread, and many governments such as those in the Canada, Australia and UK have applied forms of performance measurement. Some other governments have also started using PM.

Many U.S. states calling for some form of performance measurement [1].
In recent years, reform of the public sector in the UK and further a field has been a major focus of policy makers and academics. In the academic perspective, a great deal of literature on the area of public sector reform has been published and there have been many seminars and workshops around the world dealing with the issue. This is often encased in the New Public Management (NPM) debate [2]. However, little research has hitherto concentrated on understanding the context of performance management in practice [3]. Performance measurement systems (PMSs) have attracted a great deal of debate in the private sector, less so in the public sector and in developing countries, such as the Kingdom of Saudi Arabia. Within Saudi Arabia, a series of reform projects has attempted to introduce the notion of PMSs in the public sector. This paper aims to highlight a number of tentative findings induced from data related to the design and usage of PMSs in the educational administration in Saudi Arabia. It also attempts to highlight the factors that might influence such systems.

\section{Purpose of the study}

The overall objectives of the study are to: Develop an empirical understanding of PMSs in the educational administration in Saudi Arabia, and its relationship with contextual factors.

\section{Background statement}

In the Kingdom of Saudi Arabia, the administration of education is centralised and educational polices are controlled by the government itself. The Ministry of Education, which was established in 1953, is responsible for the education of boys and girls, at all stages in general education, that is, primary, intermediate and secondary schools.

The second institution responsible for the educational system in the Kingdom is the Ministry of Higher Education, which was established in 1975 to implement higher education policy. Scholarship, international academic relations and the Saudi 
educational offices abroad are all supervised by the Ministry of Higher Education [4].

The final institution responsible for the educational system in the Kingdom is the General Organisation of Technical Education and Vocational Training. According to Al-Huqail [5], the Saudi government realised the need for technical and vocational training and therefore established the institution, which is supervised by the Ministry of Labour and Social Affairs and is concerned with industrial, agricultural and commercial training.

The Ministry of Education is divided into eight main parts: Deputy Ministry for Public School, Agency for Education - Boys, Agency for Education - girls, Agency Planning and Development, General Directorate of Administrative and Financial Affairs, Directorate General for Information Technology, General Secretariat of the departments of Education, and General Administration of educational information. Departments of the ministry of education are distributed in fifty-seven educational regions throughout the Kingdom.

These department aims to Oversee the implementation of plans and educational programs and educational adopted for the region in the framework of the objectives, regulations and educational policies. These departments were evaluated individualy by the ministry of education with no specific measurement to evaluate the performance of the whole institutions.

In the 13th of October 2010 the ministry of education made a decision of establishing (GSDE) which aim to support the performance of educational departments by measuring the performance with accurate and scientific indicators. The organizational structure of the GSDE Is Consists of the GSED, Office of the Secretary, the unit of indicators and studies, the unit of evaluating performance and follow-up and finally the unit of educational leaders affairs.

Key Performance indicators (KPI) are specific and measurable Standards that evaluate organisational performance in specific field. There are many advantages of using indicators to measure performance in educational system, it helps to identify the main problems in managing educational system and can be used to measure to what extend goals has been achieved, the ministry of education can use indicators as an accounting tools for educational system, it can motivate employees and united them to concern of the main goals that need to be achieved, the ministry of education can use the performance measurement to create a competition between educational systems themselves in specific time or with similar systems at the level of the whole region or across the country.

There are some Mechanisms that implemented to work on the performance indicators for the Department of Education: first step is establishing a team to collect and analyse performance indicators, the second is collecting data and information and finally, creating performance indicator. Categorising educational indicators was based on the intended purpose for instance, it can be categorised by the traditional way such as teacher, school, student, the cost. It can be also categorised by the part of career such as income, outcome and process and so on.

\section{Research questions}

The research will attempt mainly to answer the question of, what theory explains the experience of performance measurement systems in the educational administration in Saudi Arabia. This question can be divided into the following sub-questions: 1 ) What is the perceived role of performance measurement systems in the Saudi educational administration? How are they developed perceived and used? 2) What factors appear to affect the way performance measurement systems are practiced in educational administration? 3) What differences in these phenomena exist between different cases? Why? 4) What further developments might be useful?

\section{Methodology}

Research can be categorised according to several methodological types. Cohen, Manion and Morrison [6] categorised research into surveys, experiments, in-depth ethnography, action research, case study research, and testing and assessment. The current study has the characteristics of qualitative, inductive research, case study. According to Corbin and Strauss [7], "qualitative research allows researchers to get at the inner experience of participants, to determine how meanings are formed through and in culture, and to discover rather than test variables" (p. 12). Cohen et al. [8] stated that "a case study provides a unique example of real people in real situations, enabling readers to understand ideas more clearly than simply by presenting them with abstract theories or principles" (p. 181).

Cohen and Manion [9] enumerate four kinds of interview that might be used as research tools: the structured interview, the unstructured interview, the non-directive interview and the focused interview. Semi-structured interviews seem the most appropriate method to use in the current study.

\subsection{The sample population}

The aim of the current study is to develop an empirical understanding of PMSs in the educational administration in Saudi Arabia, and its relationship with contextual factors. The target population is (GSDE) which aim to support the performance of educational departments by measuring the 
performance with accurate and scientific indicators. Initially, the data will be collected from GSDE), Office of the Secretary, staff in the unit of indicators and studies, staff in the unit of evaluating performance and follow-up and finally staff in the unit of educational leaders' affairs.

\section{Findings}

The findings from the twenty-four interviews were grouped into four major themes each with related sub-themes:

- The concept of PMSs

- Development and implementation

- The organisational factors affecting PMSs

\section{The first major theme: The concept of PMSs}

This theme was the first point explored and was further divided into two sub-themes:

- Responsible institutions

- Actual tasks.

Responsible institutions shows, from the participants' point of view, that some institutions are responsible of performance measurement these are: GAT, NCEI, GAEE, APD and GSED.

The director of GSED department pointed out: "Actually I cannot claim that we are the only department who take care of PMSs or KPIs. There are several departments directly or indirectly are responsible of the development of the PMS but the only department that actually working on this is the $(G S D E)^{\prime \prime}$

From the above quote the researcher made interviews with 25 interviewees in all departments and found that they do not have a clear vision about PMSs and they all mentioned that the GSDE is the only department working on the PMS. The other departments have only some basic knowledge and initial plans to work on this concept. Therefore, the researcher concentrated on GSED as the main source of practical knowledge.

Actual tasks was explained by a number of participants in the GSED as the main department working on the PMSs. A staff of GSED summarized the tasks as follows:

"Our main target of measuring performance is improving and raising the level of performance in all areas of the 45 educational administrations in the kingdom of Saudi Arabia based on the indicators which supposed to be built by all relevant departments in the ministry. However, in reality we are working alone to create good indicators".
The second major theme: Development and implementation

This theme was divided into three sub-themes:

- The previous status

- The current status

- The future status

The previous status of PMSs was not workable and ineffective as described by one of the interviewees.

"The department was established only five years ago and there were no clear indicators from our department or the others. Therefore, we started thinking about developing some indicators ourselves as we discovered that other relevant departments are not involved in the concept of PMSs".

The current status of PMSs describes the steps of improving PMSs by developing suitable indicators. These steps can be summarised as follows:

1. Requesting the 45 education administrations to develop their own indicators based on daily and real jobs.

2. Investigating what came out of these indicators and discovering weakness and strengths.

3. Developing comprehensive indicators based on the outputs of the previous steps.

4. Appointing 45 representatives in all educational administrations to implement the indicators and send the outcomes back to GSED.

5. The representatives suggested adding new indicators, which were taken into account.

6. Analyzing the outcomes and comparing the performance of educational administrations to each other, and comparing current performance indicators with the previous ones.

7. Attempting to consider international standards to be included in our indicators.

\section{The third major theme: The organisational factors} affecting PMSs

This theme explains the factors that may affect PMSs. It was divided into three sub-themes:

- Lack of cooperation

- Centralisation

- Culture

All interviewees complained about the lack of cooperation between departments in the ministry regarding PMSs. One interviewee from GSED pointed out:

"Our department should be receiving ready indicators from other departments specially $A P D$ which includes many sub-departments that can work with others to create strong and united indicators. 
Therefore, the problem is that every department has its own opinion with no clear vision. Therefore, we built the indicators and implemented them in all educational departments in the country without the knowledge of other departments"

The Second sub-theme mentioned by interviewees is centralisation. A number of other interviewees indicated that centralization leads to a situation in which most departments fail to pay attention to the quality of many duties including measuring performance, as they are busy to complete regulations each in their way. This gives them the feeling that PMSs is a new concept.

"It seems that centralisation might be suitable to cooperation under one system but in terms of PMSs it seems the opposite we are working separately regarding indicators this may because it is new concept regarding to measuring performance of all educational departments in the country" (GSED staff).

The third sub-theme mentioned by some participants is culture.

"PMSs is a new concept and centralisation has resulted in a culture of fear of accountability, as well as affecting the quality of performance and improvement in educational administrations as well as making decision to create strict indicators. You can see here that we still suffer to make clear indicators and move quickly to improve. People in the departments are not motivated to create indicators as they know that our culture refuses this kind of concept" ${ }^{\prime \prime \prime}$

\section{Discussion and Conclusion}

This research was conducted in an educational setting in Saudi Arabia, to gain an empirical understanding of PMSs in educational administration in Saudi Arabia, and its relationship with contextual factors.

As with any other study, the current one based on previous knowledge and theories built on contributions from other researchers. The current study added to this and contributed in cases where studies about PMSs are limited by offering a qualitative approach. The participants expressed their attitudes and feelings clearly, which is less feasible in the quantitative approaches. The researchers believe that PM is an important area, as it represents a critical part of the management process, which aims to universally assess how well tasks are done in contrast to a set objectives.

The research attempted to answer the following questions: 1) What is the perceived concept of PMSs in the Saudi educational administration? 2) How are
PMSs developed and who is responsible of them? 3) What factors appear to affect the way PMSs are practiced?

In terms of the first research question, it seems from the findings that several departments in the ministry are responsible of performance measurement these are: GAT, NCEI, GAEE, APD and GSED. However, it was found that the last department (GSED) is the only department that work on PMSs in reality. The reason as can be seen from the field that a group of employees in this department are well educated and believe strongly in the benefit of the concept of PMSs. Therefore, they work hard even with the lack of cooperation from other departments, which have no clear vision as discovered from the interviewees.

The department of (GSED) works alone in measuring the performance of the regional 45 administrations to improve and raise the level of their performance.

In terms of the second research question, three sub-themes was created to explain clearly how the PMSs are developed and used. This question was answered by participants in the department of GSED as they are the only department that work on the concept and developed their indicators basically by asking at the educational administrations to develop their own indicators and combined them into a comprehensive set of indicators. The researchers believe that the concept is still weak and needs more work and cooperation from other departments.

In terms of the last research question, three factors are found to affect the way PMSs are practiced. Centralisation, lack of cooperation and culture seems to be the main affecting factors on the concept PMSs. All interviewees complained about the lack of cooperation with other departments in the ministry regarding the development of PMSs. A number of interviewees indicated that centralisation leads to a situation in which most departments fail to pay attention to the quality of many duties including measuring performance, as they are busy to complete regulations each in their way. It seems that centralisation might be suitable to increase cooperation but in terms of PMSs it appears the opposite. PMSs is a new concept and centralisation has resulted in a culture of fear of accountability, as well as affecting the quality of performance and improvement in educational administrations as well as making decision to create strict indicators. You can see here that GSED still suffers to make clear indicators and move quickly to improve them. People in the departments are not motivated to create indicators, as they know that culture refuses this kind of concept.

Finally, at the end of this research, the researchers hope that the main questions were adequately addressed, opening some doors for others to think about the importance of the concept PMSs in 
improving education system in Saudi Arabia. The current qualitative research may lay the basis for further quantitative and generalisable research, to be made available to the ministry of education. In addition, this study may draw attention to future researchers' thinking deeply about the effect of centralisation on quality in the whole education system and the culture. In addition, further researchers may investigate this topic deeply by extending the investigation to include schools, educational administrations in the whole country to have a full picture about PMSs and find the deeper sources of problems. According to Alzaidi, one particular feature in the Saudi educational context is the highly centralized system. This may drew out attention to the relationship between centralization and quality.

\section{References}

[1] Hatry, H.P., Performance Measurement: Getting Results. (2d. ed.). The Urban Institute Press, Washington D.C., 2006.

[2] Hood, C. "The 'New Public Management' in the 1980s: Variations on a Theme." Accounting Organisations and Society 20, 1995 pp. 93-109.

[3] Broad, M., A. Goddard and L. V. Albert, "Performance, Strategy and Accounting in Local Government and Higher Education in the UK". Public Money \& Management, 27, 2007, pp. 119126.

[4] Al-Sunbul, A. A., Management of the education system in Saudi Arabia. In A. A. Al-Sunbul, M.S. Al-Khateeb, M. M. Mitwalli, and N.M. Abduljawad, (eds) Education System in the Kingdom of Saudi Arabia, 6th edn, Al-Kheraiji press, 1998, pp. 59-94.

[5] Al-Huqail, S., Educational system in the Kingdom of Saudi Arabia. King Fahad National Library, Riyadh, 1998.

[6] Cohen, L., L. Manion, and K. Morrison, Research methods in education. 6th ed. Routledge, Falmer, London, 2007.

[7] Corbin, J. and A. Strauss, Basics of qualitative research. SAGE Publications Ltd., United Kingdom, 2008.

[8] Cohen, L., L. Manion, and K. Morrison, Research methods in education. Routledge, Falmer, London, 2000.

[9] Cohen, L. and L. Manion, Research methods in education. Croom Helm Ltd., London, 1980. 